\title{
Geldanamycin attenuates 3-nitropropionic acid-induced apoptosis and JNK activation through the expression of HSP 70 in striatal cells
}

\author{
YONG-JOON CHOI, NAM HO KIM, MAN SUP LIM, HEE JAE LEE, SUNG SOO KIM and WANJOO CHUN \\ Department of Pharmacology, College of Medicine, Kangwon National University, \\ Chuncheon, Gangwon 200-701, Republic of Korea
}

Received February 10, 2014; Accepted April 14, 2014

DOI: $10.3892 / \mathrm{ijmm} .2014 .1747$

\begin{abstract}
Although selective striatal cell death is a characteristic hallmark in the pathogenesis of Huntington's disease (HD), the underlying mechanism of striatal susceptibility remains to be clarified. Heat shock proteins (HSPs) have been reported to suppress the aggregate formation of mutant huntingtin and concurrent striatal cell death. In a previous study, we observed that heat shock transcription factor 1 (HSF1), a major transcription factor of HSPs, significantly attenuated 3 -nitropropionic acid (3NP)-induced reactive oxygen species (ROS) production and apoptosis through the expression of HSP 70 in striatal cells. To investigate the differential roles of HSPs in 3NP-induced striatal cell death, the effect of geldanamycin (GA), an HSP 90 inhibitor, was examined in 3NP-stimulated striatal cells. GA significantly attenuated 3NP-induced striatal apoptosis and ROS production with an increased expression of HSP 70. Triptolide (TL), an HSP 70 inhibitor, abolished GA-mediated protective effects in 3NP-stimulated striatal cells. To understand the underlying mechanism by which GA-mediated HSP 70 protects striatal cells against 3NP stimulation, the involvement of various signaling pathways was examined. GA significantly attenuated 3NP-induced c-Jun N-terminal kinase (JNK) phosphorylation and subsequent c-Jun phosphorylation in striatal cells. Taken together, the present study demonstrated that GA exhibits protective properties against 3NP-induced apoptosis and JNK activation via the induction of HSP 70 in striatal cells, suggesting that expression of HSP 70 may be a valuable therapeutic target in the treatment of HD.
\end{abstract}

Correspondence to: Dr Wanjoo Chun, Department of Pharmacology, College of Medicine, Kangwon National University, Hyoja-2, Chuncheon, Gangwon 200-701, Republic of Korea E-mail:wchun@kangwon.ac.kr

Key words: Huntington's disease, geldanamycin, heat shock protein 70,3-nitropropionic acid, reactive oxygen species

\section{Introduction}

Huntington's disease (HD) is an autosomal dominant neurodegenerative disorder caused by an abnormal polyglutamine expansion within the protein huntingtin (1). Despite similar expression levels throughout the brain, mutant huntingtin selectively targets striatal neurons, with the cerebral cortex being affected later in the disease (2). Although selective striatal cell death is a prominent feature of HD, the underlying mechanism of striatal susceptibility remains to be clarified. Mitochondrial dysfunction has been reported to contribute to the pathogenesis of HD (3) and may underlie the selective neuronal degeneration (4).

Administration of 3-nitropropionic acid (3NP) in rodents and non-human primates has provided useful experimental models for HD $(5,6)$. 3NP is an irreversible inhibitor of the mitochondrial complex II, which causes energy impairment and replicates most of the clinical and pathophysiological characteristics of HD, including spontaneous choreiform and dystonic movements, as well as the selective degeneration of striatum $(6,7)$. 3NP has been reported to trigger the generation of superoxide radicals, secondary excitotoxicity and apoptosis $(7,8)$. It has been reported that the c-Jun N-terminal kinase (JNK)/c-Jun signaling pathway plays an important role in 3NP-induced striatal degeneration (5).

Heat shock proteins (HSPs) are considered important protective effectors against a variety of cellular stresses $(9,10)$. HSPs suppress protein misfolding by assisting misfolded proteins in the refolding process. For example, the overexpression of HSP 70 reduces the toxic accumulation of abnormal polyglutamine proteins and suppresses cell death in a variety of cellular models of polyglutamine diseases including HD (7,11-13). In addition, HSP 70 has been reported to block several steps of the apoptotic cascade such as upstream from mitochondria, release of cytochrome $c$ and apoptosis-inducing factor (AIF), nuclear import of AIF, activation of procaspase-9 and -3, and even downstream of active caspase-3 (10,14-19).

Geldanamycin (GA) is a benzoquinone ansamycin antibiotic that inhibits the function of HSP 90 by binding to the ADP/ATP-binding pocket of the protein (20). HSP 90 client proteins play important roles in the regulation of the cell cycle, cell growth, survival, apoptosis, angiogenesis and 
oncogenesis (20). HSP 90 is a major repressor of the heat shock transcription factor 1 (HSF1), a major transcription factor of HSPs (21). Upon binding to HSP 90, GA induces the expression of HSP 70 through the action of HSF1 $(21,22)$. It has been reported that GA activates a heat shock response and inhibits huntingtin aggregation in a cell culture model of HD (23).

The present study was conducted to examine whether GA attenuated 3NP-induced striatal damage and the underlying mechanism involved. GA exhibited an increased expression of HSP 70 and significantly suppressed 3NP-induced apoptosis, reactive oxygen species (ROS) generation, and JNK activation.

\section{Materials and methods}

Cell culture. The immortalized striatal progenitor cell line $\left(\mathrm{STHdh}^{\mathrm{Q7}}\right)$, which expresses endogenous wild-type huntingtin, was obtained from Dr Marcy E. MacDonald and maintained in Dulbecco's modified Eagle's medium (DMEM) supplemented with $10 \%$ (v/v) FBS, $10 \mathrm{U} / \mathrm{ml}$ of penicillin (all from Gibco, Invitrogen, Carlsbad, CA, USA) at $33^{\circ} \mathrm{C}$ in humidified air with $5 \% \mathrm{CO}_{2}$.

Cell viability assay. Striatal cells were plated in 6-well culture plates (Greiner Bio-One Inc., Longwood, FL, USA) and incubated at $33^{\circ} \mathrm{C}$ under $5 \% \mathrm{CO}_{2}$, and $95 \%$ humidified air incubator. The cells were incubated with GA for $4 \mathrm{~h}$ prior to treatment with $3 \mathrm{NP}$ for another $24 \mathrm{~h}$. After washing with PBS, $0.6 \mathrm{mg} / \mathrm{ml} \mathrm{3-(4,5-dimethylthiazol-2-yl)-2,5-diphenyl-}$ tetrazolium bromide (MTT) was added (100 $\mu \mathrm{l} / \mathrm{well})$ and incubated for $2 \mathrm{~h}$ at $33^{\circ} \mathrm{C}$. MTT solution $(40 \mu \mathrm{l})$ was then removed from each well and replaced with $500 \mu \mathrm{l}$ of dimethyl sulfoxide (DMSO). The plates were incubated for $1 \mathrm{~h}$ at $33^{\circ} \mathrm{C}$. Absorbance readings were taken at $570 \mathrm{~nm}$ using a Multiskan Ex microtitre plate reader (Thermo Fisher Scientific, Inc., Waltham, MA, USA). Data are expressed as \% MTT reduction compared to a $100 \%$ signal from non-transfected cells.

Lactate dehydrogenase leakage ( $L D H)$ assay. Striatal cells were exposed to $3 \mathrm{NP}(10 \mu \mathrm{M})$ overnight at $33^{\circ} \mathrm{C}$ for $24 \mathrm{~h}$. After exposure to $3 \mathrm{NP}$ and GA, the medium was centrifuged at $250 \mathrm{x} \mathrm{g}$ for $10 \mathrm{~min}$ to harvest the cell culture media and the cell-free supernatant was obtained for the LDH activity assay using a commercial LDH detection kit (Roche Diagnostics Gmbh Mannheim, Germany) according to the manufacturer's instructions.

Western blotting. Striatal cells were washed with PBS three times and lysed by PRO-PREP protein extraction solution (Intron Biotechnology, Inc., Gyeonggi, Korea), and sonicated on ice. Protein concentrations of the homogenates were measured using the BCA method (Sigma-Aldrich, St. Louis, MO, USA) and diluted to a final concentration of $2 \mathrm{mg} / \mathrm{ml}$ with $2 \mathrm{X}$ reducing stop buffer $(0.25 \mathrm{M}$ Tris- $\mathrm{HCl}$, $\mathrm{pH}$ 6.8, $5 \mathrm{mM}$ EDTA, $5 \mathrm{mM}$ EGTA, $25 \mathrm{mM}$ dithiothreitol, $2 \%$ SDS, $10 \%$ glycerol, and bromophenol blue as the tracking dye). Equal amounts of proteins were separated on 8-12\% SDS-polyacrylamide gels and transferred to a Hybond PVDF transfer membrane (GE Healthcare, Amersham, UK). The membranes were blocked in 5\% skim milk in TBST $(20 \mathrm{mM}$ Tris-HCl, $\mathrm{pH}$ 7.6, $137 \mathrm{mM} \mathrm{NaCl}, 0.05 \%$ Tween-20) for $30 \mathrm{~min}$ at room temperature and sequentially incubated with an appropriate antibody; anti-HSP 90 monoclonal antibody $(1: 1,000)$, anti-HSP 70 monoclonal antibody $(1: 1,000)$ (both from Stressgen Biotechnologies, Victoria, BC, Canada), anti-cleaved caspase-3 and total caspase-3 polyconal antibody $(1: 1,000)$, anti-Cleaved PARP and total PARP polyconal antibody $(1: 1,000)$ (Cell Signaling Technology, Inc., Danvers, MA, USA), anti-IкB- $\alpha$ monoclonal antibody (Santa Cruz Biotechnology Inc., Santa Cruz, CA, USA), total JNK and P-JNK polyconal antibody (1:1,000), anti-c-Jun and P-c-Jun polyconal antibody $(1: 1,000)$ (both from Cell Signaling Technology, Inc.) and $\beta$-actin monoclonal antibody $(1: 2,500$; Sigma-Aldrich) in the same buffer overnight at $4^{\circ} \mathrm{C}$. After thoroughly washing with TBST, the membranes were washed three times with TBST and incubated with HRP-conjugated goat anti-rabbit IgG for polyclonal antibodies, or with HRP-conjugated goat anti-mouse IgG (1:2,500; Jackson ImmunoResearch Laboratories, West Grove, PA, USA) for $2 \mathrm{~h}$ at room temperature. The membranes were rinsed three times for $30 \mathrm{~min}$ with TBST, followed by four quick rinses with distilled water, and developed with the enhanced chemiluminescence method (GE Healthcare).

FACS assay. Striatal cells were collected with a cell scraper, washed twice with cold PBS and then resuspended in $1 \mathrm{X}$ binding buffer at a concentration of $1 \times 10^{6}$ cells $/ \mathrm{ml}$. One hundred microliters of the solution $\left(1 \times 10^{5}\right.$ cells $)$ were transferred to a $5 \mathrm{ml}$ culture tube and $5 \mu \mathrm{l}$ of Annexin V-PE and $5 \mu \mathrm{l}$ of 7 -AAD were added. The mixture was gently vortexed, incubated for $15 \mathrm{~min}$ at room temperature in the dark, and $400 \mu \mathrm{l}$ of binding buffer was added to each tube. The stained cells were analyzed by flow cytometry (BD Model FACScan, BD Biosciences, Franklin Lakes, NJ, USA).

DAPI staining. For DNA fragmentation studies, striatal cells were cultured in 6-well culture plates and treated with $3 \mathrm{NP}$, GA and GA+3NP for $24 \mathrm{~h}$. After washing with PBS, the striatal cells were fixed using $1 \%$ paraformaldehyde in PBS for $20 \mathrm{~min}$, permeabilized using $0.1 \%$ Triton X-100 for $5 \mathrm{~min}$, and stained with DAPI $(1 \mu \mathrm{g} / \mathrm{ml})$ (Invitrogen Life Technologies, Carlsbad, CA, USA) for $20 \mathrm{~min}$. All steps were carried out at room temperature. Representative data were obtained by using confocal microscopy (Carl Zeiss, Inc., Thornwood, NY, USA).

Measurement of intracellular ROS production. The striatal cells were cultured on $18 \mathrm{~mm}$ round coverslip at $33^{\circ} \mathrm{C}$, $5 \% \mathrm{CO}_{2}$. After 1 day, the coverslips were transferred into the 12 -well plates and the media were changed (no phenol red media) for $1 \mathrm{~h}$ stabilization. After washing, each sample was stained by $10 \mu \mathrm{M} \mathrm{H} 2 \mathrm{DCFDA}$ (H2DCFDA, Molecular Probe cat. no. D-399, stocked $50 \mathrm{mM}$ in DMSO) for $10 \mathrm{~min}$ under culture conditions. The coverslips were washed three times with DMEM (no phenol red). Coverslips were located in the chamber, and media were added, and cells were immediately observed by confocal laser scanning microscopy (Olympus, Tokyo, Japan).

Immunocytochemistry. The effect of 3NP into the nuclear translocation of NF- $\mathrm{NB}$ was examined by immunofluorescence assay using confocal microscopy. Following treatment, the 
cells were fixed with 4\% PFA diluted in PBS for $20 \mathrm{~min}$ at room temperature and incubated for 10 min with $0.1 \%$ Triton X-100. After washing with PBS, the plates were preincubated with PBS, prior to incubation with $10 \%$ normal goat serum for $1 \mathrm{~h}$ to reduce the background at room temperature, followed by incubation with the anti-NF- $\mathrm{kB}$ antibody in PBS containing $10 \%$ normal goat serum overnight at $4^{\circ} \mathrm{C}$. The plates were rinsed and incubated with an anti-rabbit TRITC-conjugated antibody (Invitrogen Life Technologies) for $2 \mathrm{~h}$ at room temperature. After washing, the nuclei were stained with Hoechst 33258 (100 mM) (Invitrogen Life Technologies) for $10 \mathrm{~min}$ and mounted under coverslips at room temperature. Representative data were obtained by using confocal microscopy (Carl Zeiss, Inc.). The digitally stored images were combined and shown with the accompanying software and Adobe Photoshop 4.0.

Statistical analysis. Data were presented as means \pm SE obtained from at least three independent experiments. The statistical difference was analyzed by one-way ANOVA with Tukey's post-hoc test using SPSS software 12K (SPSS, Inc., Chicago, IL, USA). P $<0.05$ was considered statistically significant.

\section{Results}

GA results in the increased expression of HSP 70 and attenuates 3NP-induced apoptosis in striatal cells. To examine the effect of GA, an HSP 90 inhibitor, in the expression of HSPs, the expression levels of HSP 70 and HSP 90 were examined. GA resulted in the increased expression of HSP 70 (Fig. 1A). However, the expression level of HSP 90 was not significantly changed with GA, which inhibits the function of HSP 90 by binding to the ADP/ATP-binding pocket of the protein.

In order to examine the effect of GA on the viability of 3NP-stimulated striatal cells, the cells were treated with 3NP in the absence or presence of GA. Significant striatal cell death was observed with 3NP treatment in MTT and LDH assays (Fig. 2A and B). However, GA significantly attenuated 3NP-induced striatal cell death. In addition, the number of positive cells of 7-AAD and FITC, which indicate dead cells, was significantly reduced with GA in the FACS analysis (Fig. 2Ca and b).

Given the fact that 3NP induces striatal cell death in the present study, we examined whether 3NP induces apoptosis and whether GA attenuated 3NP-induced striatal cell death. Treatment of 3NP resulted in the cleavage of caspase-3 and PARP, which indicate the activation of apoptosis (Fig. 3A). GA significantly attenuated 3NP-induced production of active caspase-3 and cleaved PARP in striatal cells (Fig. 3A). In addition, GA significantly reduced the number of 3NP-induced apoptotic nuclei (Fig. 3B).

GA attenuates $3 N P$-induced ROS production. We have previously reported that the overexpression of HSF1 significantly attenuated 3NP-induced ROS production in striatal cells (7). To investigate the effects of GA in 3NP-induced ROS production, the intracellular ROS generation was measured in the absence or presence of GA in 3NP-challenged striatal cells. Treatment of 3NP resulted in the production of a considerable
$\mathbf{A}$

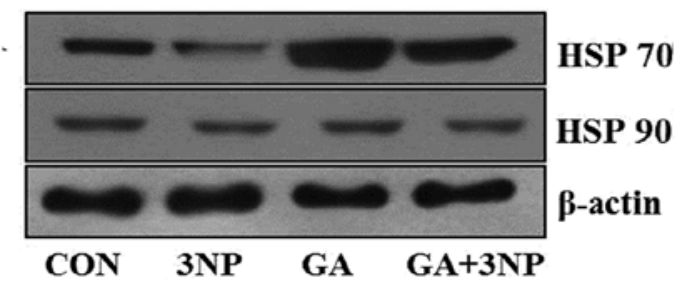

B

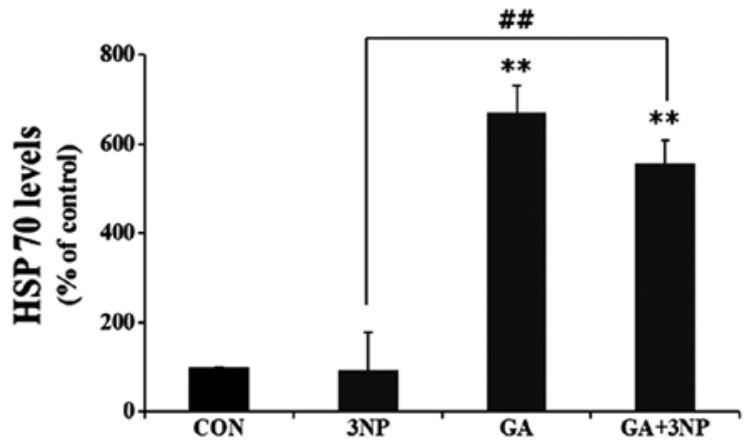

C



Figure 1. Geldanamycin (GA)-induced expression of heat shock protein (HSP) 70 in striatal cells. (A) Striatal cells were treated with $500 \mathrm{nM}$ GA and incubated in the presence or absence of $10 \mu \mathrm{M} 3$-nitropropionic acid (3NP). After $24 \mathrm{~h}$ of incubation, HSP 70 and HSP 90 were assessed by immunoblotting. HSP 70 expression was increased by GA, whereas expression of HSP 90 did not change. Loading control was confirmed by $\beta$-actin. (B and C) Quantitative analysis was obtained from three individual experiments $(n=3){ }^{* *} \mathrm{P}<0.01$ indicates significant differences compared to the control. ${ }^{\# \#} \mathrm{P}<0.05$ indicates significant differences between the indicated groups.

amount of the intracellular ROS in striatal cells. GA significantly attenuated 3NP-induced ROS production, albeit not completely (Fig. 4). Fig. 4A shows a representative confocal image of intracellular level of ROS and Fig. 4B shows quantitative analysis of ROS production. The result demonstrates that GA protects cells by inhibiting the production of ROS in 3NP-challenged striatal cells.

GA attenuates 3NP-induced I $\kappa B$ degradation and nuclear translocation of $N F-\kappa B$. It has been reported that ROS facilitates cell death by inducing inflammatory responses via the activation of NF- $\kappa B$-mediated transcription (24-26). ІкB inhibits the nuclear translocation of NF- $\mathrm{KB}$ by retaining it in cytoplasm. Under stress conditions, I $\mathrm{B}$ proteins are rapidly degraded by the proteasome, and released NF- $\mathrm{KB}$ translocates 

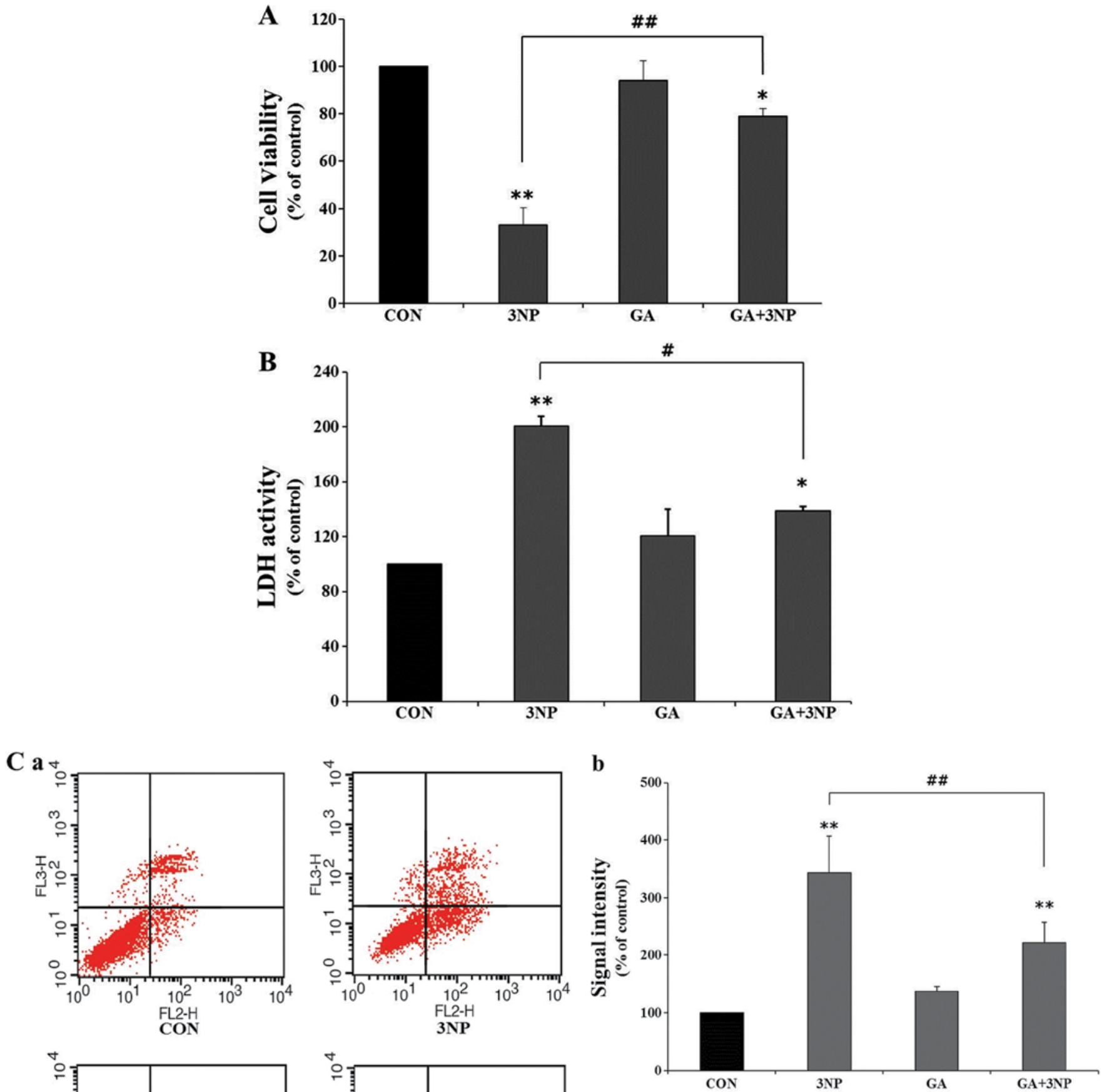

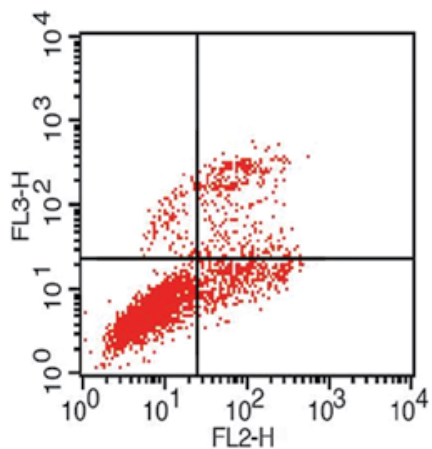

GA

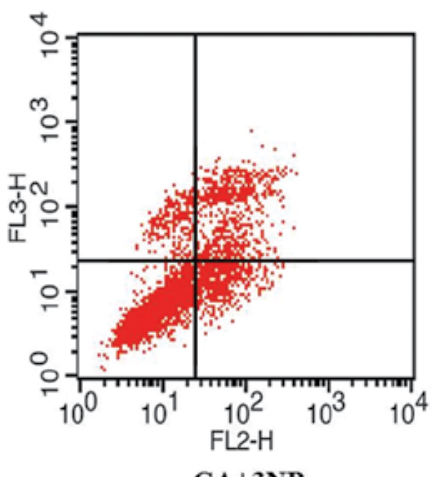

GA+3NP

Figure 2. Protective effects of geldanamycin (GA) on the cytotoxicity of 3-nitropropionic acid (3NP). (A and B) Cell viability was examined with 3-(4,5-dimethylthiazol-2-yl)-2,5-diphenyltetrazolium bromide (MTT) assay and lactate dehydrogenase leakage (LDH) assay. Striatal cells were treated with $10 \mu \mathrm{M} 3 \mathrm{NP}$, $500 \mathrm{nM}$ and their combination as indicated. After $24 \mathrm{~h}$, MTT and LDH assays were performed. GA significantly attenuated 3NP-induced cytotoxicity in striatal cells, albeit not completely. Data are shown as mean \pm SD from three individual experiments $(n=3)$. (Ca) Representative FACS images and $(\mathrm{Cb})$ quantitative analysis of FACS data. Striatal cells were incubated in the presence or absence of $3 \mathrm{NP}$ after treatment of GA. FACS assay was carried out to determine initiation and amplitude of apoptotic dell death. Only Annexin V-positive cells were indicated as early apoptotic cells and Annexin V-and 7-AAD-positive cells were considered as late apoptotic cells. The number of total apoptotic cells, which are positive to both Annexin-5 and 7-AAD, was significantly decreased in presence of GA compared to only 3NP. Data were obtained from four independent experiments $(n=4)$. ${ }^{*} \mathrm{P}<0.05$ and ${ }^{* * *} \mathrm{p}<0.01$ indicate differences compared to the control. ${ }^{\#} \mathrm{P}<0.05$ and ${ }^{\# \#} \mathrm{p}<0.01$ indicates significant differences between the indicated groups. 

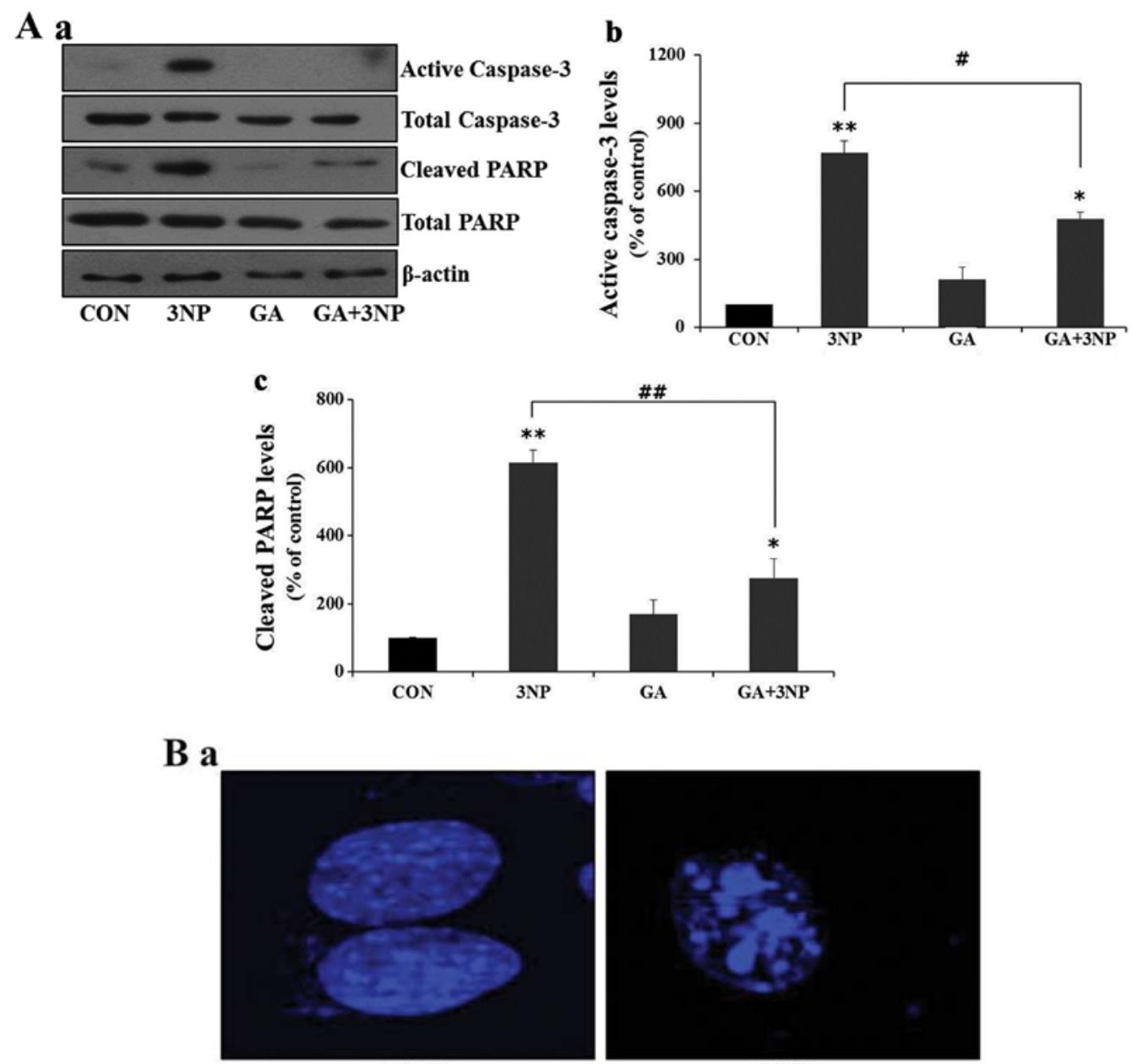

$\mathrm{CON}$

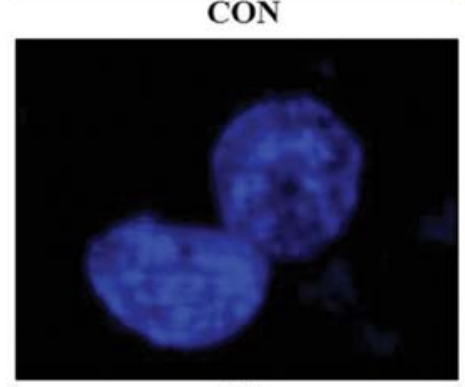

GA
$3 N P$

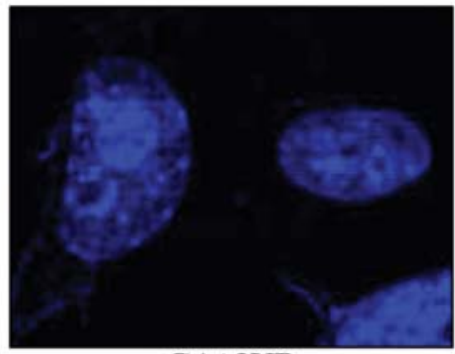

GA+3NP

b

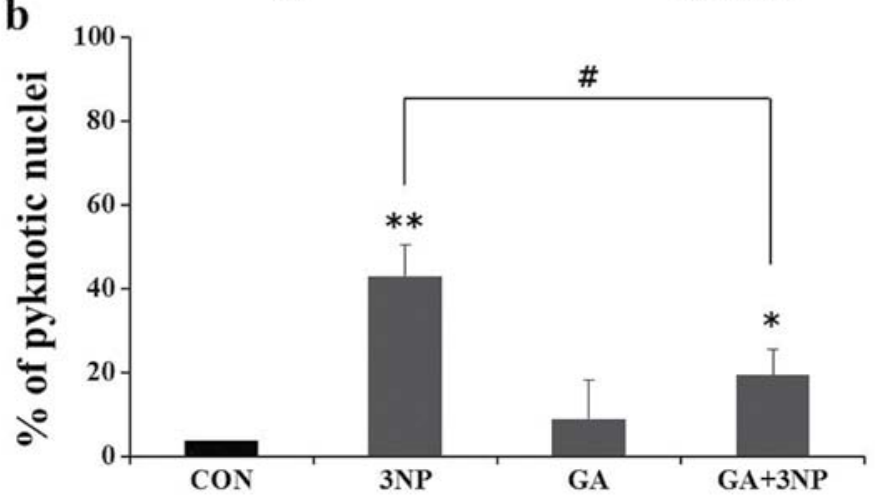

Figure 3. Effects of 3-nitropropionic acid (3NP) and geldanamycin (GA) on apoptosis. Striatal cells were treated with GA, 3NP and GA+3NP. (Aa) After $24 \mathrm{~h}$ of treatment, cells were collected and protein extracts prepared from each samples were analyzed by immunoblotting using indicated antibodies. GA suppressed 3NP-induced caspase-3 activation and level of cleaved PARP. $\beta$-actin was used as a loading control. (Ab and c) Quantitative analysis was obtained from three individual experiments $(\mathrm{n}=3)$. The nuclear morphological changes are shown by $3 \mathrm{NP}$-treated striatal cells. (Ba) The abrogation of nuclear damage by GA was measured using DAPI staining and $(\mathrm{Bb})$ quantitative analysis of apoptotic cells. The more apoptotic cells were observed in only $3 \mathrm{NP}$ treated striatal cells compared to GA+3NP-treated striatal cells. Apoptotic cells were quantitatively counted using a microscope. In only $3 \mathrm{NP}-170$-treated striatal cells, $42 \%$ of cells showed DNA fragmentation whereas $\sim 21 \%$ of cells included fragmentation in GA+3NP-treated striatal cells. Approximately 100 DAPI-positive cells were counted in each experiment. Quantitative analysis was obtained from three individual experiments $(n=3)$. ${ }^{*} \mathrm{P}<0.05,{ }^{* *} \mathrm{p}<0.01$ indicate significant differences compared to the control. ${ }^{\#} \mathrm{P}<0.05,{ }^{\# \#} \mathrm{p}<0.01$ indicates significant differences between the indicated groups. 


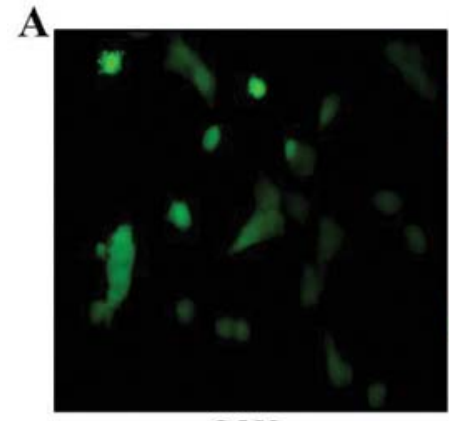

CON

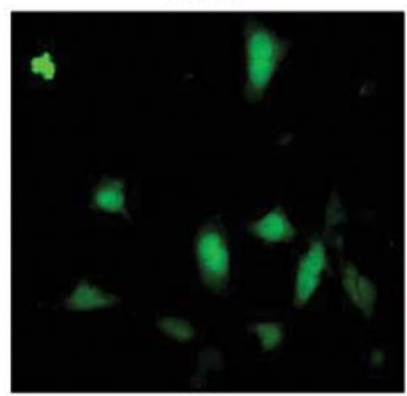

GA

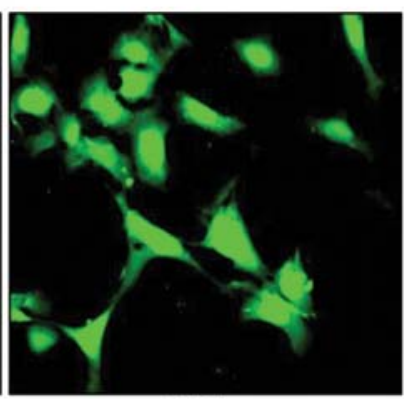

$3 N P$

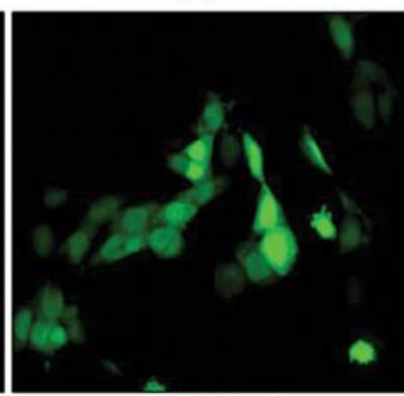

GA+3NP

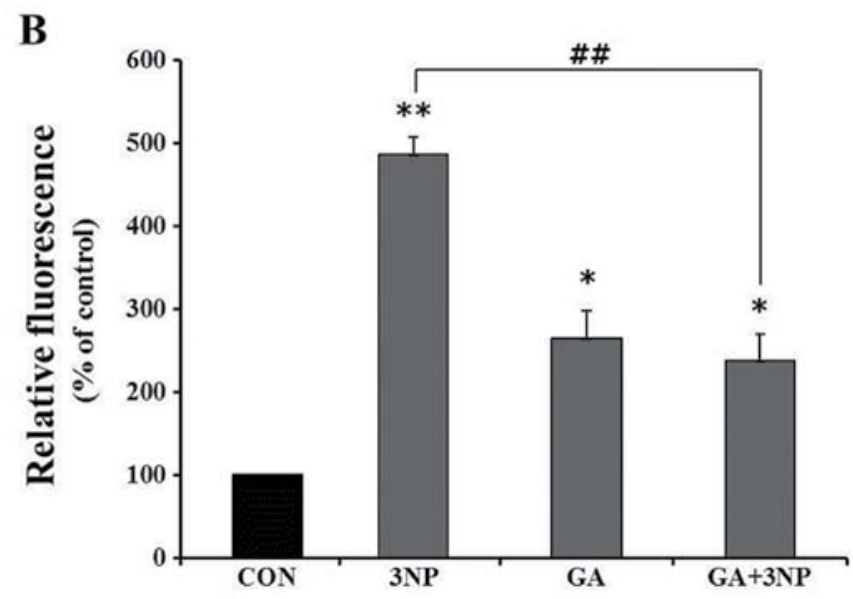

Figure 4. Geldanamycin (GA) significantly reduced intracellular reactive oxygen species (ROS) generation by 3-nitropropionic acid (3NP). (A) Intracellular level of ROS was measured using confocal microscopy. Striatal cells were treated with GA and incubated in the presence or absence of 3NP. Cells were incubated with fluorescence probe H2DCFDA $(10 \mu \mathrm{M})$. (B) H2DCFDA fluorescence was quantitatively analyzed with Fluoview 300 software. The production of 3NP-induced ROS was significantly attenuated by GA in striatal cells. Results are the means \pm SD of three independent experiments performed in triplicate. ${ }^{*} \mathrm{P}<0.05,{ }^{* *} \mathrm{p}<0.01$ indicate significant differences compared to the control. ${ }^{\# \#} \mathrm{P}<0.05$ indicates significant differences between the indicated groups.

into the nucleus to activate apoptotic pathways. To examine whether GA has an impact on $\mathrm{NF}-\kappa \mathrm{B}$ transcription, the effects of $\mathrm{GA}$ on $\mathrm{I} \kappa \mathrm{B}$ degradation and the nuclear translocation of $\mathrm{NF}-\kappa \mathrm{B}$ were examined. Treatment of 3NP markedly depleted intracellular I $\mathrm{B}$ in striatal cells. However, GA significantly attenuated 3NP-induced I $\mathrm{B}$ degradation (Fig. 5A). To confirm whether the nuclear translocation of $\mathrm{NF}-\kappa \mathrm{B}$ was affected by change at the intracellular level of $\mathrm{I} \kappa \mathrm{B}$, intracellular localization of $\mathrm{NF}-\kappa \mathrm{B}$ was examined with immunocytochemistry. Treatment of $3 \mathrm{NP}$ obviously increased the nuclear translocation of p65 subunit of NF- $\kappa$ B (Fig. 5B). Geldanamycin significantly attenuated the nuclear translocation of NF- $\kappa \mathrm{B}$ in $3 \mathrm{NP}$-challeged striatal cells (Fig. 5Ba and b).

Triptolide (TL) abrogates GA-mediated HSP 70 expression. Given the hypothesis that HSP 70 plays an important role in GA-mediated cellular protection in 3NP-challenged striatal cells, the effect of GA was examined in the absence of HSP 70 expression. The depletion of HSP 70 expression was achieved with TL, which inhibits the endogenous HSP 70 gene expression (27). TL downregulated HSP 70 expression in a concentration-dependent manner in striatal cells without affecting HSP 90 expression (Fig. 6A). To investigate the role of TL in GA-mediated cellular protection, cell viability was examined. TL showed negligible cytotoxicity at a concentration range used in the present study. However, TL significantly abolished GA-mediated cellular protection against $3 \mathrm{NP}$ treatment (Fig. 6B and C). The results strongly suggested that HSP 70 plays an essential role in GA-mediated cellular protection in 3NP-challenged striatal cells.

GA inhibits 3NP-induced JNK and c-Jun phosphorylation. It has been previously reported that activation of JNK plays a key role in 3NP-induced striatal neurodegeneration (5). 
A a

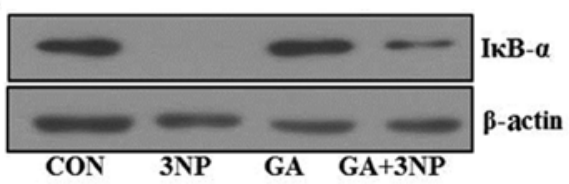

b

CON 3NP GA GA+3NP

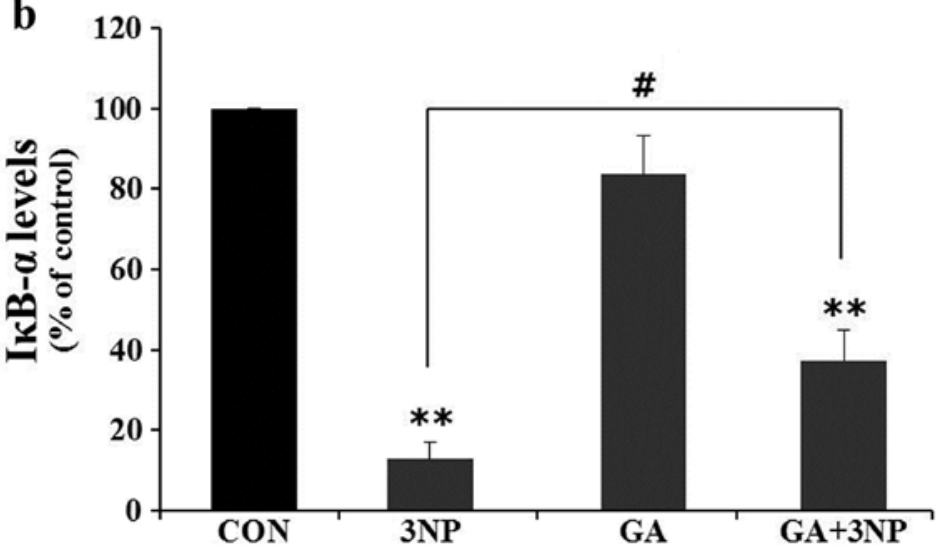

B a
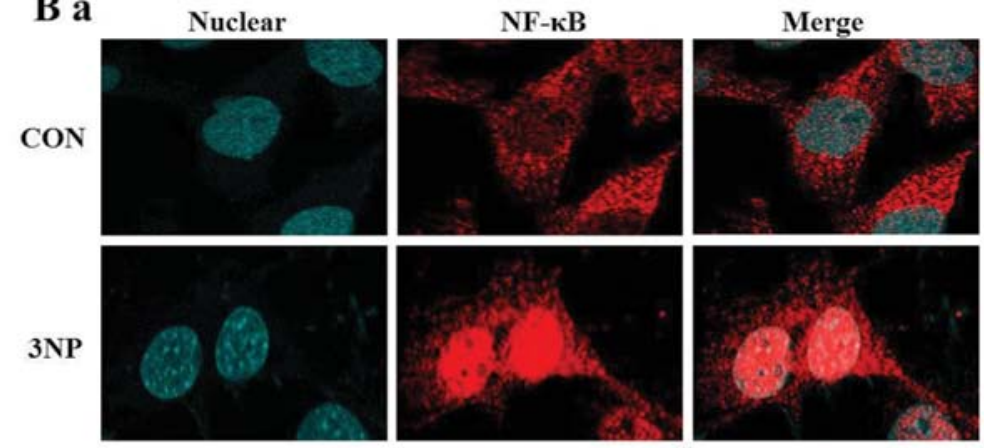

GA
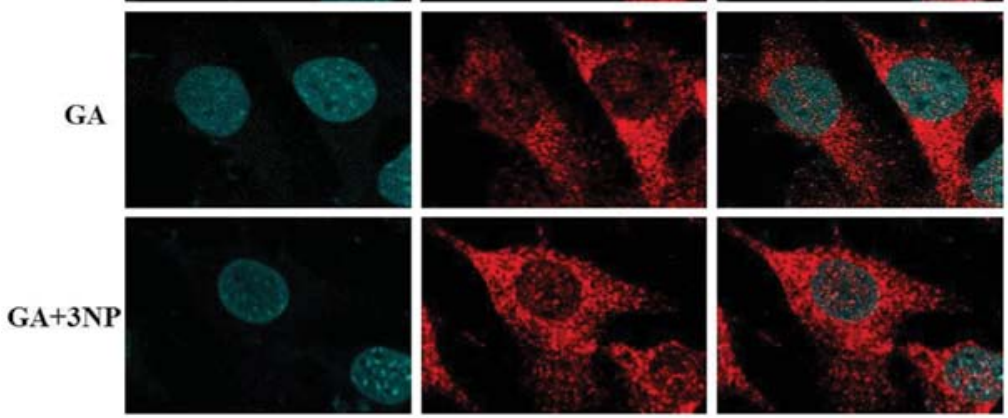

b

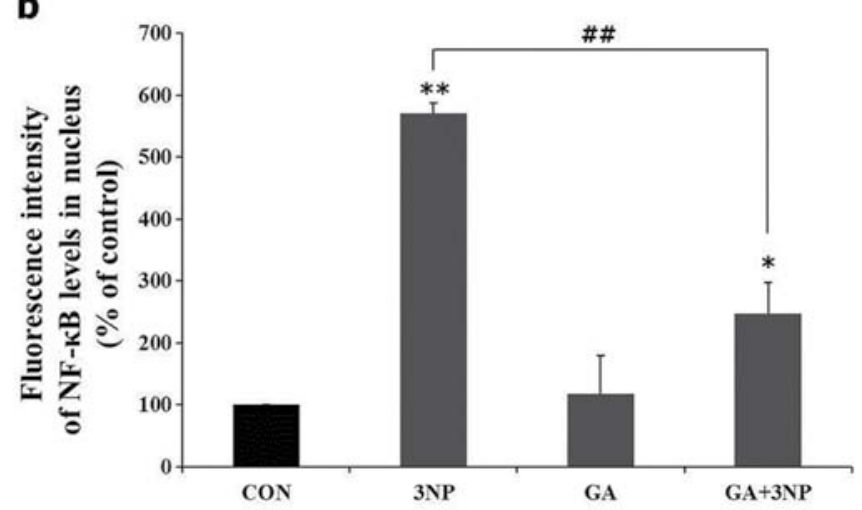

Figure 5. Geldanamycin (GA) inhibited 3-nitropropionic acid (3NP)-induced IкB degradation and nuclear translocation of NF-кB. Striatal cells were treated with GA, 3NP, GA+3NP or were untreated (control). (Aa) After $24 \mathrm{~h}$ of incubation, total proteins were extracted for immunoblotting of IkB- $\alpha$. Degradation of IкB- $\alpha$ attenuated the GA+3NP group compared to the $3 \mathrm{NP}$-only group. $\beta$-actin was used as a loading control. (Ba) Nuclear translocation of NF- $\kappa \mathrm{B}$ was examined using immunocytochemistry assay. NF- $\mathrm{kB}$ (red panels) was mainly localized in the cytoplasm (control and GA). Nuclear translocation of NF- $\mathrm{kB}$ was facilitated only in 3NP compared to GA+3NP. Nuclei were visualized by Hoechst staining (Hoechst 33258). (Ab and Bb) Quantitative analysis was obtained from three individual experiments $(\mathrm{n}=3) .{ }^{*} \mathrm{P}<0.05,{ }^{* *} \mathrm{p}<0.01$ indicate significant differences compared to the control. ${ }^{\#} \mathrm{P}<0.05$, ${ }^{\# \#} \mathrm{p}<0.01$ indicates significant differences between the indicated groups. 

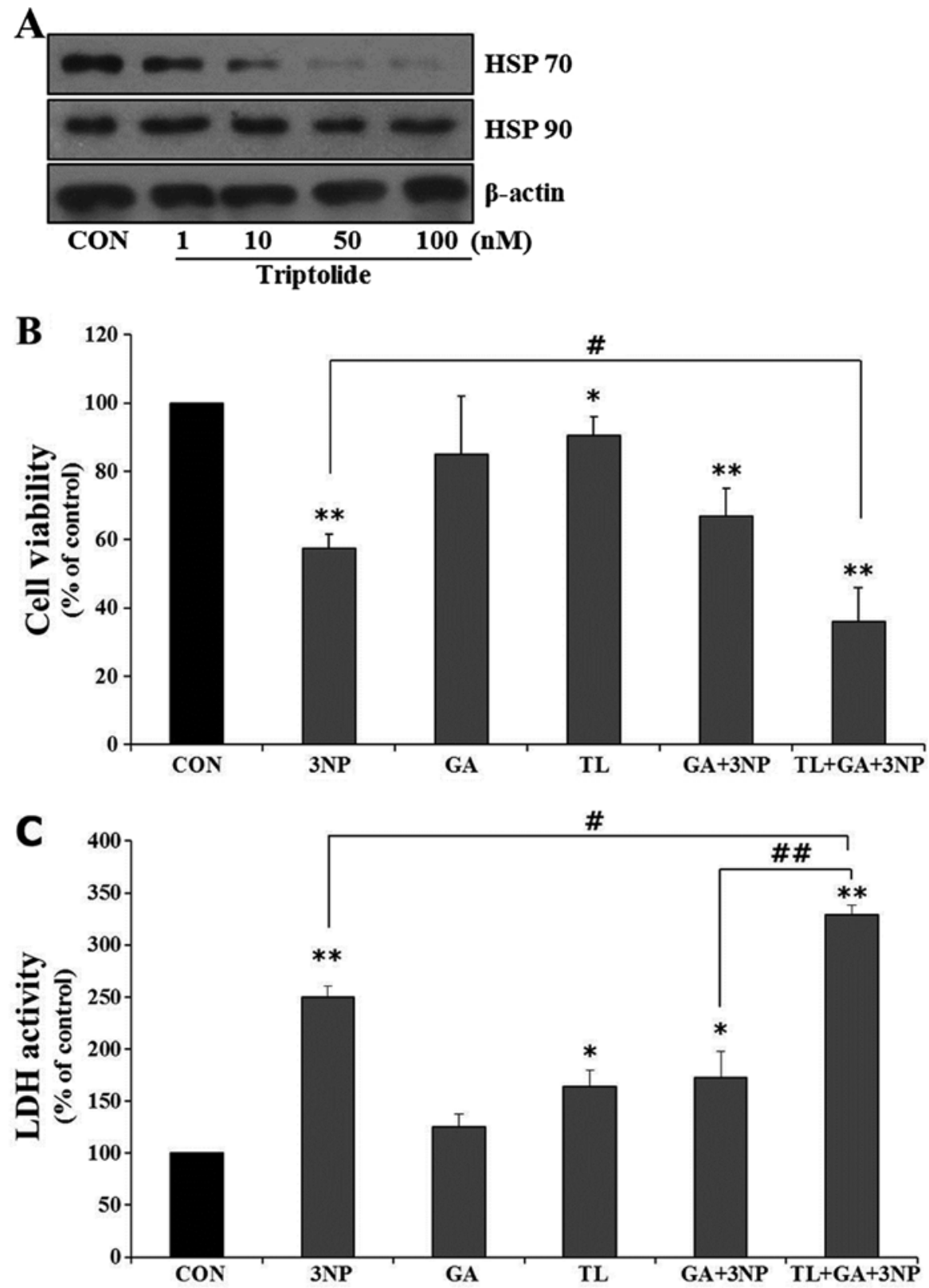

Figure 6. Triptolide (TL) inhibits the expression of heat shock protein (HSP) 70 and abrogates protective effect by geldanamycin (GA). (A) Striatal cells were treated with indicated concentration of TL. After $2 \mathrm{~h}$, cells were harvested for immunoblotting of HSP 70 and HSP 90 . Expression of HSP 70 was inhibited in a dose-dependent manner by TL, while no change was observed for HSP $90 . \beta$-actin was used as a loading control. TL significantly attenuated the protective effect of GA against 3-nitropropionic acid (3NP)-induced cell death. (B and C) Cell viability was examined with 3-(4,5-dimethylthiazol-2-yl)-2,5-diphenyltetrazolium bromide (MTT) assay and lactate dehydrogenase leakage (LDH) assay. Prior to treatment with 3NP, striatal cells were incubated for $2 \mathrm{~h}$ with TL, an inhibitor of HSP 70. TL did not cause cell death at a concentration of $50 \mathrm{nM}$ used in the present study. Data were obtained from four independent experiments $(\mathrm{n}=4)$ and expressed as mean $\pm \mathrm{SD} .{ }^{*} \mathrm{P}<0.05$ and ${ }^{* *} \mathrm{p}<0.01$ indicate significant differences compared to the control. ${ }^{\#} \mathrm{P}<0.05$ and ${ }^{\# \#} \mathrm{p}<0.01$ indicates significant differences between the indicated groups.

Therefore, the effects of GA on 3NP-induced JNK activation and subsequent c-Jun phosphorylation were examined in the present study. Treatment of $3 \mathrm{NP}$ resulted in the activation of JNK (Fig. 7A). However, GA significantly attenuated JNK phosphorylation in 3NP-challenged striatal cells (Fig. 7A). In addition, GA significantly suppressed 3NP-induced c-Jun phosphorylation in striatal cells. The data strongly demonstrate that the JNK/c-Jun signaling pathway is an important molecular pathway in 3NP-induced striatal damage and that GA exerts a cellular protective effect through suppression of the JNK/c-Jun pathway.

\section{Discussion}

The present study has demonstrated that GA significantly suppressed 3NP-induced apoptotic cell death and ROS generation through the expression of HSP 70 in a striatal cell model. GA also significantly attenuated the $3 \mathrm{NP}$-induced activation of the JNK/c-Jun signaling pathway.

HSPs have been reported to attenuate protein aggregation and neurodegeneration in HD models $(28,29)$. HSP 70 expression was increased in oxidative stress conditions, which is presumably considered a cellular compensatory mechanism 



Figure 7. Geldanamycin (GA) inhibits the phosphorylation of c-Jun N-terminal kinase (JNK)/c-Jun via mediation of heat shock protein (HSP) 70. Striatal cells were treated with GA, 3-nitropropionic acid (3NP) and GA+3NP. (A) After $4 \mathrm{~h}$ of treatment, cells were harvested and total proteins were extracted for immunoblotting of JNK and c-Jun. Treatment of GA resulted in the significant suppression of phosphorylation of JNK/c-Jun by 3 NP. $\beta$-actin was used as a loading control. (B and C) Quantitative analysis of immunoblots was obtained from three individual experiments $(\mathrm{n}=3)$. ${ }^{*} \mathrm{P}<0.05$, ${ }^{* * *} \mathrm{p}<0.01$ indicate significant differences compared to the control. ${ }^{\#} \mathrm{P}<0.05,{ }^{\# \#} \mathrm{p}<0.01$ indicates significant differences between the indicated groups.

against oxidative stresses (14,30-33). It has been reported that inducers of HSP 70 significantly suppressed toxicity of mutant huntingtin in a $C$. elegans model (34). Recently, we observed that the overexpression of HSF1 resulted in a significantly increased expression of HSP 70 and attenuated apoptosis in 3NP-challenged striatal cells (7). In addition, inhibition of HSP 70 function with methylene blue significantly abolished HSF1-mediated protection against 3NP-induced striatal damage (7), suggesting that HSP 70 plays a major role in HSF1-mediated anti-apoptotic action in striatal cells. In the present study, inhibition of HSP 70 gene expression with TL also significantly attenuated GA-mediated protection in striatal cells, confirming that HSP 70 plays an essential role in cellular protection in $3 \mathrm{NP}$-challenged striatal cells.
HSP 90 is constitutively expressed in mammalian cells and plays an essential role in facilitating the proper folding, maturation, and activity of its client proteins (35), which eventually regulates a variety of cellular events including cell survival, apoptosis, and oncogenesis (20). HSP 90 associates with its client proteins in an ATP-dependent manner $(36,37)$. GA specifically interferes with this association by occupying the ATP-binding pocket of HSP 90 and dissociates client proteins from the protein (38-40). HSP 90 has also been reported to be a major repressor of HSF1 (21). It has been reported that GA induces the expression of HSPs such as HSP 70 and HSP 40 and inhibits huntingtin aggregation in a cell culture model of HD (23). In that study, HSPs significantly attenuated the mutant huntingtin-induced toxicity and the number of mutant 
huntingtin aggregates. However, it has also been reported that HSPs did not affect the aggregate formation of mutant huntingtin (41), suggesting that HSPs may exert its protective actions independent of suppression of aggregate formation. Therefore, more studies are necessary to elucidate the exact mechanism by which HSPs exert cytoprotection in the pathogenesis of HD. In the present study, GA exhibited an increased expression of HSP 70 and a significant suppression of apoptotic cell death ROS production in 3NP-challenged striatal cells. GA has also been reported to protect against MPTP-induced dopaminergic neurotoxicity through the induction of HSP 70 in an animal model (42).

Mitochondrial dysfunctions have been reported to be involved in the pathogenesis of HD (43). Individuals with HD showed a decreased mitochondrial enzyme activities in the striatum $(44,45)$ and mitochondria from HD patients were shown to be more sensitive to apoptosis (46). Mitochondrial toxin $3 \mathrm{NP}$ produces selective striatal lesions $(47,48)$ and clinical features of HD such as choreiform movements and locomotor dysfunction $(49,50)$. $3 \mathrm{NP}$ is known to induce striatal neurodegeneration via the activation of the JNK/c-Jun signaling pathway (5). Activation of JNK occurred progressively and selectively in the striatum and c-Jun activation was followed in the same striatal region (5). Furthermore, overexpression of the dominant negative form of c-Jun completely abolished $3 \mathrm{NP}$-induced striatal neurodegeneration, indicating that the JNK/c-Jun signaling pathway is an important molecular event in 3NP-induced striatal degeneration (5). In the present study, significantly increased phosphorylation of JNK and c-Jun was observed with $3 \mathrm{NP}$ treatment in striatal cells, confirming that JNK/c-Jun signaling pathway is crucial in 3NP-induced striatal toxicity.

HSP 70 has been reported to block JNK activation and prevent apoptosis in response to protein-damaging and physiological stimuli (51-53). HSP 70 modulates the activity of JNK through direct binding to the protein (54) and that HSP 70 deficiency results in activation of the JNK signaling pathway (55). Recently, it has been reported that HSP 70 inhibits the JNK signaling pathway and subsequently prevents Bax-mediated apoptosis (56). In the present study, inhibition of HSP 70 gene expression with TL significantly abolished GA-mediated striatal survival against 3NP-induced cell death, suggesting that HSP 70 may be a major mediator for the suppression of JNK/c-Jun activation in striatal cells. However, more studies are necessary to clearly understand the mechanism by which geldanamycin-induced HSP 70 inhibits the JNK/c-Jun signaling pathway in 3NP-challenged striatal cells.

Taken together, the present study clearly demonstrates that GA exerts anti-apoptotic properties such as suppression of apoptosis and JNK/c-Jun signaling in 3NP-challenged striatal cells presumably through the expression of HSP 70, suggesting that GA may be a valuable therapeutic agent to increase the intracellular level of HSP 70, which plays a beneficial role in the pathogenesis of HD.

\section{Acknowledgements}

The authors would like to thank Dr Marcy E. MacDonald for the generous gift of the striatal cell line. This study was supported by the Basic Science Research Program through the National
Research Foundation of Korea (NRF) funded by the Ministry of Education, Science and Technology (C1010000-01-01).

\section{References}

1. Andrew SE, Goldberg YP, Kremer B, et al: The relationship between trinucleotide (CAG) repeat length and clinical features of Huntington's disease. Nat Genet 4: 398-403, 1993.

2. Vonsattel JP and DiFiglia M: Huntington disease. J Neuropathol Exp Neurol 57: 369-384, 1998.

3. Beal MF: Mitochondria take center stage in aging and neurodegeneration. Ann Neurol 58: 495-505, 2005.

4. Oliveira JM, Jekabsons MB, Chen S, et al: Mitochondrial dysfunction in Huntington's disease: the bioenergetics of isolated and in situ mitochondria from transgenic mice. J Neurochem 101: 241-249, 2007.

5. Garcia M, Vanhoutte P, Pages C, Besson MJ, Brouillet E and Caboche J: The mitochondrial toxin 3-nitropropionic acid induces striatal neurodegeneration via a c-Jun $\mathrm{N}$-terminal kinase/c-Jun module. J Neurosci 22: 2174-2184, 2002.

6. Brouillet E, Condé F, Beal MF and Hantraye P: Replicating Huntington's disease phenotype in experimental animals. Prog Neurobiol 59: 427-468, 1999.

7. Choi YJ, Om JY, Kim NH, et al: Heat shock transcription factor-1 suppresses apoptotic cell death and ROS generation in 3-nitropropionic acid-stimulated striatal cells. Mol Cell Biochem 375: 59-67, 2013.

8. Dedeoglu A, Ferrante RJ, Andreassen OA, Dillmann WH and Beal MF: Mice overexpressing 70-kDa heat shock protein show increased resistance to malonate and 3-nitropropionic acid. Exp Neurol 176: 262-265, 2002.

9. Takayama S, Reed JC and Homma S: Heat-shock proteins as regulators of apoptosis. Oncogene 22: 9041-9047, 2003.

10. Beere HM, Wolf BB, Cain K, et al: Heat-shock protein 70 inhibits apoptosis by preventing recruitment of procaspase-9 to the Apaf-1 apoptosome. Nat Cell Biol 2: 469-475, 2000.

11. Cummings CJ, Mancini MA, Antalffy B, DeFranco DB, Orr HT and Zoghbi HY: Chaperone suppression of aggregation and altered subcellular proteasome localization imply protein misfolding in SCA1. Nat Genet 19: 148-154, 1998.

12. Kobayashi Y, Kume A, Li M, et al: Chaperones Hsp70 and Hsp40 suppress aggregate formation and apoptosis in cultured neuronal cells expressing truncated androgen receptor protein with expanded polyglutamine tract. J Biol Chem 275: 8772-8778, 2000.

13. Wyttenbach A, Swartz J, Kita H, et al: Polyglutamine expansions cause decreased CRE-mediated transcription and early gene expression changes prior to cell death in an inducible cell model of Huntington's disease. Hum Mol Genet 10: 1829-1845, 2001.

14. Mosser DD, Caron AW, Bourget L, Denis-Larose C and Massie B: Role of the human heat shock protein hsp70 in protection against stress-induced apoptosis. Mol Cell Biol 17: 5317-5327, 1997.

15. Jäättelä M, Wissing $D$, Kokholm K, Kallunki T and Egeblad M: Hsp70 exerts its anti-apoptotic function downstream of caspase-3-like proteases. EMBO J 17: 6124-6134, 1998.

16. Mosser DD, Caron AW, Bourget L, et al: The chaperone function of hsp70 is required for protection against stress-induced apoptosis. Mol Cell Biol 20: 7146-7159, 2000.

17. Ravagnan L, Gurbuxani S, Susin SA, et al: Heat-shock protein 70 antagonizes apoptosis-inducing factor. Nat Cell Biol 3: 839-843, 2001.

18. Gurbuxani S, Schmitt E, Cande C, et al: Heat shock protein 70 binding inhibits the nuclear import of apoptosis-inducing factor. Oncogene 22: 6669-6678, 2003.

19. Koga F, Xu W, Karpova TS, McNally JG, Baron R and Neckers L: Hsp90 inhibition transiently activates Src kinase and promotes Src-dependent Akt and Erk activation. Proc Natl Acad Sci USA 103: 11318-11322, 2006

20. Schulte TW, Akinaga S, Soga S, et al: Antibiotic radicicol binds to the N-terminal domain of Hsp90 and shares important biologic activities with geldanamycin. Cell Stress Chaperones 3: 100-108, 1998

21. Zou J, Guo Y, Guettouche T, Smith DF and Voellmy R: Repression of heat shock transcription factor HSF1 activation by HSP90 (HSP90 complex) that forms a stress-sensitive complex with HSF1. Cell 94: 471-480, 1998. 
22. Bagatell R, Paine-Murrieta GD, Taylor CW, et al: Induction of a heat shock factor 1-dependent stress response alters the cytotoxic activity of hsp90-binding agents. Clin Cancer Res 6: 3312-3318, 2000.

23. Sittler A, Lurz R, Lueder G, et al: Geldanamycin activates a heat shock response and inhibits huntingtin aggregation in a cell culture model of Huntington's disease. Hum Mol Genet 10: 1307-1315, 2001.

24. Bian X, McAllister-Lucas LM, Shao F, et al: NF-kappa B activation mediates doxorubicin-induced cell death in N-type neuroblastoma cells. J Biol Chem 276: 48921-48929, 2001.

25. Bubici C, Papa S, Pham CG, Zazzeroni F and Franzoso G: The NF-kappaB-mediated control of ROS and JNK signaling. Histol Histopathol 21: 69-80, 2006

26. Dumont A, Hehner SP, Hofmann TG, Ueffing M, Dröge W and Schmitz ML: Hydrogen peroxide-induced apoptosis is CD95-independent, requires the release of mitochondria-derived reactive oxygen species and the activation of NF-kappaB. Oncogene 18: 747-757, 1999.

27. Westerheide SD, Kawahara TL, Orton K and Morimoto RI: Triptolide, an inhibitor of the human heat shock response that enhances stress-induced cell death. J Biol Chem 281 9616-9622, 2006.

28. Wyttenbach A: Role of heat shock proteins during polyglutamine neurodegeneration: mechanisms and hypothesis. J Mol Neurosci 23: 69-96, 2004.

29. Muchowski PJ and Wacker JL: Modulation of neurodegeneration by molecular chaperones. Nat Rev Neurosci 6: 11-22, 2005.

30. Ciocca DR, Clark GM, Tandon AK, Fuqua SA, Welch WJ and McGuire WL: Heat shock protein hsp70 in patients with axillary lymph node-negative breast cancer: prognostic implications. J Natl Cancer Inst 85: 570-574, 1993.

31. Dive C and Hickman JA: Drug-target interactions: only the first step in the commitment to a programmed cell death? Br J Cancer 64: 192-196, 1991.

32. Seo JS, Park YM, Kim JI, et al: T cell lymphoma in transgenic mice expressing the human Hsp70 gene. Biochem Biophys Res Commun 218: 582-587, 1996

33. Wei YQ, Zhao X, Kariya Y, Teshigawara K and Uchida $A$ : Inhibition of proliferation and induction of apoptosis by abrogation of heat-shock protein (HSP) 70 expression in tumor cells. Cancer Immunol Immunother 40: 73-78, 1995.

34. Haldimann P, Muriset M, Vigh L and Goloubinoff P: The novel hydroxylamine derivative NG-094 suppresses polyglutamine protein toxicity in Caenorhabditis elegans. J Biol Chem 286 : 18784-18794.

35. Neckers L: Hsp90 inhibitors as novel cancer chemotherapeutic agents. Trends Mol Med 8: S55-S61, 2002.

36. Panaretou B, Prodromou C, Roe SM, et al: ATP binding and hydrolysis are essential to the function of the Hsp90 molecular chaperone in vivo. EMBO J 17: 4829-4836, 1998.

37. Grenert JP, Johnson BD and Toft DO: The importance of ATP binding and hydrolysis by hsp90 in formation and function of protein heterocomplexes. J Biol Chem 274: 17525-17533, 1999.

38. Schneider C, Sepp-Lorenzino L, Nimmesgern E, et al: Pharmacologic shifting of a balance between protein refolding and degradation mediated by Hsp90. Proc Natl Acad Sci USA 93: 14536-14541, 1996.

39. Connell P, Ballinger CA, Jiang J, et al: The co-chaperone CHIP regulates protein triage decisions mediated by heat-shock proteins. Nat Cell Biol 3: 93-96, 2001.
40. Xu W, Marcu M, Yuan X, Mimnaugh E, Patterson C and Neckers L: Chaperone-dependent E3 ubiquitin ligase CHIP mediates a degradative pathway for c-ErbB2/Neu. Proc Natl Acad Sci USA 99: 12847-12852, 2002.

41. Wacker JL, Huang SY, Steele AD, et al: Loss of Hsp70 exacerbates pathogenesis but not levels of fibrillar aggregates in a mouse model of Huntington's disease. J Neurosci 29: 9104-9114, 2009.

42. Shen HY, He JC, Wang Y, Huang QY and Chen JF: Geldanamycin induces heat shock protein 70 and protects against MPTP-induced dopaminergic neurotoxicity in mice. J Biol Chem 280: 39962-39969, 2005.

43. Beal MF: Energetics in the pathogenesis of neurodegenerative diseases. Trends Neurosci 23: 298-304, 2000.

44. Gu M, Gash MT, Mann VM, Javoy-Agid F, Cooper JM and Schapira AH: Mitochondrial defect in Huntington's disease caudate nucleus. Ann Neurol 39: 385-389, 1996.

45. Browne SE, Bowling AC, MacGarvey U, et al: Oxidative damage and metabolic dysfunction in Huntington's disease: selective vulnerability of the basal ganglia. Ann Neurol 41: 646-653, 1997.

46. Sawa A, Wiegand GW, Cooper J, et al: Increased apoptosis of Huntington disease lymphoblasts associated with repeat length-dependent mitochondrial depolarization. Nat Med 5: 1194-1198, 1999

47. Beal MF, Brouillet E, Jenkins BG, et al: Neurochemical and histologic characterization of striatal excitotoxic lesions produced by the mitochondrial toxin 3-nitropropionic acid. J Neurosci 13: 4181-4192, 1993.

48. Hamilton BF and Gould DH: Nature and distribution of brain lesions in rats intoxicated with 3-nitropropionic acid: a type of hypoxic (energy deficient) brain damage. Acta Neuropathol 72: 286-297, 1987.

49. Brouillet E, Hantraye P, Ferrante RJ, et al: Chronic mitochondrial energy impairment produces selective striatal degeneration and abnormal choreiform movements in primates. Proc Natl Acad Sci USA 92: 7105-7109, 1995.

50. Palfi S, Ferrante RJ, Brouillet E, et al: Chronic 3-nitropropionic acid treatment in baboons replicates the cognitive and motor deficits of Huntington's disease. J Neurosci 16: 3019-3025, 1996.

51. Gabai VL, Meriin AB, Yaglom JA, Volloch VZ and Sherman MY: Role of Hsp70 in regulation of stress-kinase JNK: implications in apoptosis and aging. FEBS Lett 438: 1-4, 1998.

52. Meriin AB, Yaglom JA, Gabai VL, et al: Protein-damaging stresses activate c-Jun N-terminal kinase via inhibition of its dephosphorylation: a novel pathway controlled by HSP72. Mol Cell Biol 19: 2547-2555, 1999.

53. Kyriakis JM and Avruch J: Protein kinase cascades activated by stress and inflammatory cytokines. Bioessays 18: 567-577, 1996.

54. Park HS, Lee JS, Huh SH, Seo JS and Choi EJ: Hsp72 functions as a natural inhibitory protein of c-Jun N-terminal kinase. EMBO J 20: 446-456, 2001.

55. Lee JS, Lee JJ and Seo JS: HSP70 deficiency results in activation of c-Jun N-terminal Kinase, extracellular signal-regulated kinase, and caspase-3 in hyperosmolarity-induced apoptosis. J Biol Chem 280: 6634-6641, 2005.

56. Li H, Liu L, Xing D and Chen WR: Inhibition of the JNK/Bim pathway by Hsp70 prevents Bax activation in UV-induced apoptosis. FEBS Lett 584: 4672-4678, 2010. 